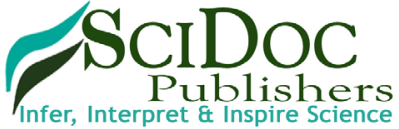

International Journal of Surgery and Research (IJSR)

ISSN 2379-156X

\title{
Synthetic Vasopressin and Oxytocin Analogs and Their Potential Use in Hemorrhagic, Traumatic and Septic Shock: A Personal Perspective
}

Editorial

\author{
Altura $\mathrm{BM}^{1-5^{*}}$, Gebrewold A ${ }^{1}$, Carella A $\mathrm{A}^{1}$, Altura BT $\mathrm{B}^{1,3-5}$ \\ ${ }^{1}$ Department of Physiology and Pharmacology, The State University of New York Downstate Medical Center, Brooklyn, New York, USA. \\ ${ }^{2}$ Department of Medicine, The State University of New York Downstate Medical Center, Brooklyn, New York, USA. \\ ${ }^{3}$ Center for Cardiovascular and Muscle Research, The State University of New York Downstate Medical Center, Brooklyn, New York, USA. \\ ${ }^{4}$ The School of Graduate Studies in Molecular and Cellular Science, The State University of New York Downstate Medical Center, Brooklyn, \\ New York, USA. \\ ${ }^{5}$ Bio-Defense Systems, Inc, Rockville Center, New York, USA.
}

As one of us has stated many years ago, "shock is a significant and sustained loss of effective circulating blood volume [1]. It will eventuate in hypoperfusion of critical peripheral tissues, thus leading to a deficit in transcapillary exchange function in critical organ regions [1-3]. Clinically, there are five major types of circulatory shock: cardiogenic; septic; distributive; anaphylactic; and hypovolemic [1-3]. Hypovolemic shock (HS) is, primarily, due to a marked decrease in venous return, falling arterial blood pressure, and ventricular preload, and usually is caused by hemorrhage, dehydration, excessive diarrhea, trauma, excessive fluid loss from severe burns, increased positive intrathoracic pressure, excessive urinary fluid loss resulting from diuretics, side effects of many chemotherapeutic agents and radiation in cancer patients, or depressed vasomotor tone in the microcirculation [13].

Septic shock is often termed "a vasodilatory shock" and is a leading cause of morbidity and mortality in the USA and Europe [1-4]. Septic shock and traumatic shock both involve substantial fluid loss, and often are treated with catecholamines, inotropic agents and corticosteroids in an attempt to maintain arterial blood pressure, venous return and distribution to key peripheral tissues and organs [1-5]. However, this often results in decreased cardiac output, intense ischemia in multiple organ regions and/or tachyphylaxis to the drugs and worsening of the patient, increased morbidity and mortality.

Whatever circumstances initiate the "low-flow state" (hemorrhage, trauma, sepsis, etc.) and whatever the effects these initiating circumstances may have on circulating blood volume and cardiac output, the overall vasomotor response results in a functional decrease in transcapillary exchange in the peripheral tissues $[6,7]$. This is the all-important trigger mechanism that sets in motion the chain of events which, if not promptly corrected, will generate the refractory and ultimately irreversible characteristics of the shock syndrome, that is, inadequate tissue blood flow and the attendant ischemia resulting in multiple microcirculatory organ-tissue failure. The strategic role of microcirculatory failure in "low-flow states" is firmly supported by voluminous studies which demonstrate that any therapy which directly or indirectly improves local tissue blood flow is beneficial [1-9]. But most of these studies do not emphasize drugs or techniques that are either suitable or reliable for clinical use in a "tried-and-true-manner".

Many different drugs are commonly used to raise arterial blood pressure in states of circulatory shock; these being referred to as "vasopressors". Although the idea to utilize these agents to raise arterial blood pressure is, at first glance, a reasonable hemodynamic basis for their use, they are often discarded because while they often raise blood pressure, they do not effectively increase tissue perfusion [1-3, 8, 9]. The net effects of these vasopressors on the pressure-resistance relationships (P-R) which determine blood flows in the periphery are often incompatible with either increased blood flow or increased survival of the patient. Despite these drawbacks new vasopressors continually are searchedfor. What physicians, surgeons, and ER people often forget is that in "low-flow states", local tissue blood flows are primarily conditioned by postarteriolar microcirculatory dynamics $[1-3,9]$. Effective drugs must be able to pharmacologically modify the postarteriolar muscular microvessels (metarterioles, precapillary sphincters, and venules) to sustain effective capillary blood flows, distribution, and outflow (i.e., venous return) $[6,7,9]$. For more

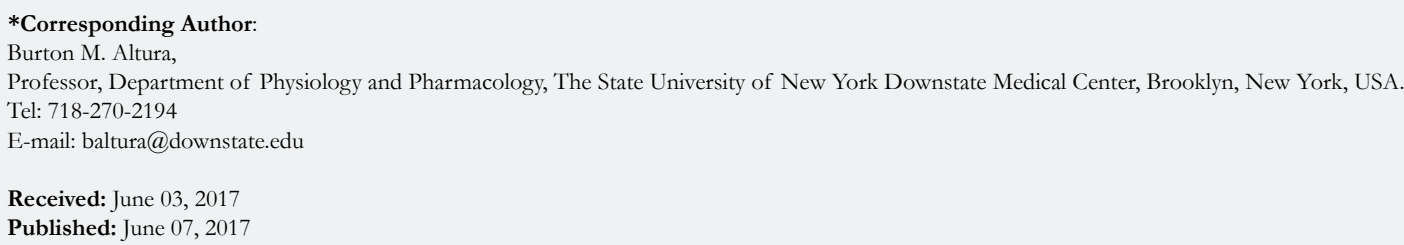

Copyright: Altura $\mathbf{B M}^{\circ}$ 2017. This is an open-access article distributed under the terms of the Creative Commons Attribution License, which permits unrestricted use, distribution and reproduction in any medium, provided the original author and source are credited. 
than 50 years, our laboratories have used this principle to design and implement the use of "selective vasopressor agents" [10-36]. We have done this by altering or directing the synthesis of new drugs by changing the molecular structures of vasopressin (VP) and oxytocin [OT] [10-36].

Until recently, neither VP nor OT were given little serious thought as useful vasoctive drugs; VP because of its well-documented coronary and unselective peripheral constrictor actions [6-9], and OT because of its very "iffy" cardiovascular actions. VP has been shown, in numerous animal and human studies, to cause reductions in coronary arterial flows that become severe, resulting in ischemia [37-45]. However, some studies suggest that this may not either happen or VP may induce vasodilatation (in pulmonary and cerebral vascular beds [45], despite evidence to the contrary [37-45]. This controversy might be related to different actions on the major, surface coronaries versus the smaller arterioles deep within the walls of the ventricles. Another factor that has to be considered in all forms of circulatory shock, is that there is a massive release of VP from the paraventricular and supraoptic nuclei of the hypothalamus which often will reach levels in the blood which are from 20-200 times normal [45]. In addition, it has been demonstrated that the heart muscle has the capacity also to release VP $[44,45]$. Added to this is the number of studies which have shown that administration of VP in shock added to the endogenous release of VP often causes decreases in cardiac output and decreases in perfusion of the intestinal tract, kidneys and liver [43-45]. These affects can and often lead to lifethreatening situations. On a molar basis, VP is one of the most powerful peripheral vasoconstrictor agents, even more powerful than angiotensin II [43-45]. Most arteries and arterioles (including coronary vessels), in the body, show greater contractile sensitivity to VP compared to angiotensin II, in terms of both affinity and intrinsic activity $[19,21,33,35,36]$. However, evidence has accumulated to suggest some synthetic analogs of VP and OT may not cause coronary vasoconstrictor effects, and may actually produce coronary arterial relaxation of the vascular smooth muscle cells in intact human hearts, resulting in vasodilator actions [46-49].

Six synthetic analogs of VP, namely [2-phenylalanine, 8-lysine] vasopressin (PLV-2), [8-ornithine] vasopressin (OV), [2-phenylalanine, 8-ornithine] vasopressin (POV), [3-Ileu, 8-ornithine] vasopressin (ILV), 1-deamino-[2-phenylalanine,8arginine] vasopressin (DAVP) and [2-phenylalanine, 3-isoleucine, 8-ornithine] vasopressin (PIOV) as well as at least four analogs of OT (i.e., [8-ornithine] oxytocin; [8-arginine] oxytocin; [4-threonine] oxytocin; and 1-deamino-dicarba-oxytocin) may have significant vasodilator properties on the coronary circulation and exert ceilings on vasoconstriction in the peripheral microcirculation along with selective actions on the muscular venules in the latter [[12-36, 49]; unpublished findings]. Our ongoing animal (i.e., rat, rabbit, and dog) and human studies have determined the functional contributions to, and interactions with, the amino, phenolic, hydroxyl, and aromatic groups as well as basicity in positions 1,2,3 and 8, respectively, to or with hormonereceptor affinity and intrinsic (contractile/relaxant) activity, were determined by analyzing the dose-response curves of $10 \mathrm{VP}$ and OT octapeptides lacking one or more of these functional groups. The findings, so far, demonstrate that: 1) the structure-action relationships for the peptide-induced responses (i.e.,contractions/ relaxations) on the microvessels and various arterial blood vessels (including the coronaries) vary with the particular microand macrovessel type (i.e., arteriole, precapillary sphincter, and venule) [[12-36] unpublished findings]; 2) the amino, phenolic and aromatic groups in positions 1,2, and 3, respectively, are not only important for hormone-receptor affinity but intrinsic activity as well $[16,17,19,22-27,33,35,36]$; 3) the potency (EC 50) values for arginine-VP as well as well as the potencies and intrinsic activities of synthetic VP and OT analogs varied with the type of micro-and macrovessel examined [16, 17, 19, 22-27, 33, 35, 36]; 4) many of the VP and OT analogs (e.g., PLV-2, DVAP, POV, PIOV, [5-ornithine]-oxytocin, [4-threonine]-oxytocin ) produced various degrees of vasodilatation in intact and isolated coronary arteries, including in humans [[33, 35, 36, 49]; unpublished findings $]$; and 5) several of the modified octapeptides significantly improved permanent survival in animals and humans subjected to different forms of circulatory shock i.e., hemorrhage, trauma, sepsis, and combined injuries) $[11,12,14,15,18,23,31,32,49]$; unpublished findings]. Examination of the microvascular beds (i.e., intestine, skeletal muscle, brain, and myocardium) using high-resolution, quantitative in-situ microscopy with TV-image intensification (up to 3,600 x times normal), 31P-nuclear magnetic resonance spectroscopy, and optical spectroscopy showed that many of the VP and OT analogs, unlike norepinephrine, phenylephrine or angiotensin II, restored near-normal vasomotion, increased true capillary blood flows, prevented loss of venular vasomotor tone, increased tissue oxygenation, prevented loss of mitochondrial cytochrome oxidase, and prevented stasis of blood cells in the postcapillary vessels, thus maintaining a "vis-a-tergo" ( maintenance of venous return to the heart) despite fluid and blood loss.

Pharmacologic manipulation of the functional behavior of organ systems is by no means a novel or impractical concept; it is a well-established objective in clinical pharmacology. Renal function, for example, can be manipulated with almost exquisite precision. Comparable manipulation of the terminal vascular bed for correction of impaired tissue blood flow is also a longrecognized objective of circulatory shock and "low-flow state" therapy. Failure of microcirculatory-dependent tissue perfusion is the accepted primary event leading to irreversibility. The cardiovascular dynamics which initiate and sustain low-flow relate essentially to an untenable imbalance in the P-R relationships in critical portions of the peripheral circulation. It, thus, follows that use of vasotropic drugs which can rectify the unphysiologic $\mathrm{P}-\mathrm{R}$ factors constitutes a valid therapeutic principle. The practical problem in shock therapy is not one of principle of therapy, but of availability of the appropriate vasoactive agents. Use of this principle outlined, here, has been hampered by the lack of selective vasotropic agents, based on quantitative microcirculatory studies, as shown by our group using diverse animal models of shock, trauma and sepsis. The treatment of circulatory shock with vasoactive drugs could be more effective than present circumstances if agents with more selective actions like VP and OT analogs on the heart and on different types of vessels in the peripheral circulation were used. We believe, at this point in time, the outlook for effective and precise pharmacologic manipulation of the cardiovascular system, in circulatory shock states, is very much alive and optimistic. It is our hope that clinical trials, in shock and trauma patients, with some of the promising VP and OT analogs discussed, herein, will get underway in the near future. 


\section{Acknowledgements}

Some of the original studies and thoughts needed for the discovery of the approaches taken by our group, and reviewed above, were initiated while two of us (BMA and BTA) were at New York University School of Medicine and The Albert Einstein College of Medicine of Yeshiva University. Some of the original studies reviewed, above, were supported, in part, by N.I.H. grants from The N.H.L.B.I., ADAMHA, The N.I.D.A. and N.I.A.A.A. as well as unrestricted grants from Sandoz Pharmaceuticals and The UpJohn Co. The authors are indebted to many colleagues, over many years, who helped to make our studies and background experiments possible. The authors are also grateful to Professors Solomon G. Hershey (deceased) and Louis R. Orkin (deceased) who suggested several animal models to us as well as provided generous financial support. The authors are indebted to Dr. B. Berde (deceased, Sandoz Pharmaceuticals, Basel) and Professor Josef Rudinger (deceased, formerly of Czechoslovak Academy of Sciences, Prague and The Swiss Federal Institute, Zurich) who were instrumental in helping to synthesize many of the peptides we have utilized.

\section{References}

[1]. Altura BM, Lefer AM, Schumer W (1983) Handbook of Shock and Trauma. Raven Press, New York 1:1.

[2]. Suteu I, Bandila T, Cafrita A, Bucur A, Candea V (1977) Shock: Pathology, Metabolism, Shock Cell Treatment. Abacus Press, England.

[3]. Baue AE (1990) Multiple Organ Failure. Patient Care and Prevention. Mosby Year Book, Inc, St Louis.

[4]. Majno G, Joris I (2004) Cells, Tissues and Diseases. Oxford Univ Press, New York.

[5]. Shoemaker WC, Ayres S, Grenvik A, Holbrook PR, Thompson WL (1989) Textbook of Critical Care (2nd edn.) WB Saunders Co., Philadelphia.

[6]. Altura BM (1983) Endothelium, reticuloendothelial cells, and microvascular integrity: Roles in host defense. In: Handbook of Shock and Trauma. Raven Press, New York 1:51-95.

[7]. Altura BM (1985) Microcirculatory regulation and dysfunction: relation to RES function and resistance to shock and trauma. In: The Reticuloendothelial System, Reichard SM, Filkins JP. Plenum Press, New York 7: 353-395.

[8]. Arturson G (1969) Aspects of peripheral circulation in shock. In: International Anesthesiology Clinics, vol 7. Little Brown and Co.,Boston.

[9]. Hershey SG (1964) Shock. Little brown and Co., Boston.

[10]. Altura BM, Hershey SG (1965) Effects of a synthetic analogue of vasopressin on vascular smooth muscle. Proc Soc Exp Biol Med 119: 258-261.

[11]. Altura BM, Hsu R, Mazzia VDB, Hershey SG (1965) Influence of vasopressors on survival after traumatic, intestinal ischemic and endotoxin shock in rats. Proc Soc Exp boil Med 119: 389-393.

[12]. Altura BM, Hershey SG, Mazzia VDB (1966) Microcirculatory approach to vasopressor therapy in intestinal ischemic (SMA) shock. Am J Surg 111: $186-92$.

[13]. Altura BM (1966) Differential actions of polypeptides and other drugs on coronary inflow vessels. Am Heart J 72: 709-711.

[14]. Hershey SG, Altura BM (1966) Influence of vasoexcitor pressor drugs on microvascular injury in shock. Bibl Anat 9: 33-37.

[15]. Altura BM, Hershey SG (1967) Use of reticuloendothelial phagocytic function as an index in shock therapy. Bull NY Acad Med 43: 259-266.

[16]. Altura BM, Hershey SG (1967) Pharmacology of neurohypohyseal hormones and their synthetic analogues in the terminal vascular bed. Structureactivity relationships. Angiology 18:428-439.

[17]. Altura BM (1971) Pharmacology of neurohypophyseal hormones and analogs on isolated vascular muscle and in the terminal vascular bed. Proceedings Symposium Physiology and Pharmacology of Vascular neuroeffector Systems, Interlaken, 1969. Karger, Basel, 274-290.

[18]. Altura BM, Hershey SG, Altura BT (1970) Microcirculatory actions of vasoactive polypeptides and their use in the treatment of experimental shock. Adv Exp Biol Med 21: 399-408.

[19]. Altura BM (1970) Significance of amino residues in vasopressin on contraction in vascular smooth muscle. Am J Physiol 219: 222-229.

[20]. Altura BM (1971) Chemical and humoral regulation of blood flow through the precapillary sphincter. Microvasc Res 3: 361-384
[21]. Altura BM (1972) Can metarteriolar vessels occlude their lumens in response to vasoactive substances? Proc Soc Exp Biol Med 140: 1270-1274.

[22]. Altura BM (1972) Significance and interaction of the amino acid residues in positions 1, 2,3 and 8 of vasopressin on contractile activity in vascular smooth muscle. In: Chemistry and Biology of Peptides. Ann Arbor Science Publ, AnnArbor,p 441-447.

[23]. Altura BM, Hershey SG (1972) A structure-activity basis for vasotropic peptide therapy in shock. Adv Exp Med Biol 21: 399- 408.

[24]. Altura BM (1973) Selective microvascular constrictor actions of some neurohypohyseal peptides. Eur J Pharmacol 24: 49-60.

[25]. Altura BM (1973) Significance of amino acid residues in position 8 of vasopressin on contraction in rat blood vessels. Proc Soc Exp Biol Med 142: 1104-1110.

[26]. Altura BM (1974) Neurohypophyseal hormones and analogues: Rat pressor potency versus contractile potency on rat arterioles and arteries. Proc Soc Exp Biol Med 146: 1054-1060

[27]. Altura BM (1975) Dose-response relationships for arginine vasopressin and synthetic analogs on three types of rat blood vessels: possible evidence for regional differences in vasopressin receptor sites within a mammal. J Pharmacol Exp Ther 193: 413-423.

[28]. Altura BM, Altura BT (1975) Magnesium-neurohypophyseal hormone interactions in contraction of arterial smooth muscle. In: Peptides: Chemistry, Structure and Biology, Walter R, Meienhofer J, eds. Ann Arbor Science Publ., Ann Arbor, p 719-727.

[29]. Altura BM (1975) Sex and estrogens and responsiveness of terminal arterioles to neurohypophyseal hormones and catecholamines. J Pharmacol Exp Ther 193: 403-412.

[30]. Altura BM (1975) Magnesium-neurohypophyseal hormone interactions in contraction of vascular smooth muscle. Am J Physiol 228:1615-1620.

[31]. Altura BM (1976) DVAP: A vasopressin analog with selective microvascular and RES actions for the treatment of circulatory shock in rats. Eur J Pharmacol 37: 155-167.

[32]. Altura BM (1976) Microcirculatory approach to the treatment of circulatory shock with a new analog of vasopressin, [2-phenylalanine, 8-ornithine] vasopressin. J Pharmacol Exp Ther 198: 187-196.

[33]. Altura BM, Altura BT (1977) Vascular smooth muscle and neurohypophyseal hormones. Federation Proc 36: 1853-1860.

[34]. Altura BM (1978) Pharmacology of venular smooth muscle: New insights. Microvasc Res 16: 91-117.

[35]. Altura BM (1981) Pharmacology of the microcirculation. In : Microcirculation, Abrams DA, ed. Academic Press, New York ,p 51-105.

[36]. Altura BM, Altura BT (1984) Actions of vasopressin, oxytocin, and synthetic analogs on vascular smooth muscle. Federation Proc 43: 80-86.

[37]. Berde B (1965) Some observations on the circulatory effects of oxytocin, vasopressin and similar polypeptides. In: Advances in Oxytocin Research, Pinkerton JHM, ed. Pergamon Press, London, p 11.

[38]. Boissonnas RA (1960) The chemistry of oxytocin and vasopressin . In: Polypeptides which Affect Smooth Muscls and Blood Vessels, Schachter M, ed. Pergamon Press, London, p7.

[39]. Saameli K (1968) The circulatory actions of the neurohypophyseal hormones and similar polypeptides. In: Handbook of Experimental Pharmacology, vol 23, Berde B, ed. Springer-Verlag, Berlin, p 545.

[40]. Somlyo AP, Somlyo AV (1970) Vascular smooth muscle II. Pharmacology of normal and hypertensive vessels. Pharmacol Rev 22: 249-353. https://www. ncbi.nlm.nih.gov/pubmed/4393387

[41]. Nakano J (1973) Cardiovascular actions of vasopressin. Jap Circ J 37:363381.

[42]. Maturi MF, Martin SE, Markle D, Maxwell M, Burruss CR, et al. (1991) Coronary vasoconstriction induced by vasopressin. Production of myocardial ischemia in dogs by constrictionof nondiseased small vessels. Circulation 83: 2111-2121.

[43]. Holmes CL, Landry DW, Granton JT (2004) Science review: Vasopressin and the cardiovascular system part 2-clinical physiology. Crit Care 8: 15-23( DOI $10.1186 / \mathrm{cc} 2338$.

[44]. Japundzic-Zigon N (2013) Vasopressin and oxytocin in control of the cardiovascular system. Current Neuropharmacol 11: 218-230.

[45]. Pelletier J-S, Dicken B, Bigam D, Cheung P-Y (2014) Cardiac effects of vasopressin. J Cardiovasc Pharmacol 64: 100-107.

[46]. Hunter ME, Gordon R (1966) Laboratory and clinical studies of 2-phenylalanine-8-lysine vasopressin (Octapressin). Canad Anaesth Soc J 13: 40-47.

[47]. Katz RL (1965) Epinephrine and PLV-2: cardiac rhythm and local vasoconstrictor effects. Anesthesiol 26: 619-623.

[48]. Katz RL, Katz GJ (1966) Surgical infiltration of pressor drugs and their interaction with volatile anesthetics. Br J Anaesth 38: 712-716.

[49]. Hershey SG, Altura BM (1966) Manipulation of the peripheral circulation with vasoactive drugs in the management of shock: A microcirculatory approach. Schweiz Med Wschr 96: 1467-1471; 1516-1522 (2 parts in German). 